\title{
Estratégias e dificuldades encontradas na comercialização de hortifrutícolas em São
} Luís - MA

\author{
Strategies and difficulties encountered in the commercialization of horticultural products in São \\ Luís - MA
}

Estrategias y dificultades encontradas en la comercialización de productos hortícolas en São Luís MA

Tharcisio Campos Coelho
ORCID: https://orcid.org/0000-0003-4771-8872
Universidade Estadual do Maranhão, Brasil
E-mail: tharcisiocampos@ gmail.com
Monique Gabrielle Reis Ferreira
ORCID: https://orcid.org/0000-0002-2610-4858
Universidade Estadual do Maranhão, Brasil
E-mail: moniqueferreira88.mf@ gmail.com
Matheus Barbosa de Abreu Cutrim
ORCID: https://orcid.org/0000-0003-1944-7235
Universidade Estadual do Maranhão, Brasil
E-mail: matheuscutrim28@gmail.com
David Harisson Santos Bezerra
ORCID: https://orcid.org/0000-0003-0772-5066
E-mail: davidsemam @gmail.com
Antônio Costa Neto
Secretaria de Meio Ambiente e Controle Urbano de Maracanaú, Brasil
ORCID: https://orcid.org/0000-0001-5347-9068
Instituto Federal de Educação do Ceará, Brasil
E-mail: antonio.costa@ifce.edu.br
Carmen Hellen da Silva Rocha
ORCID: https://orcid.org/0000-0002-1674-4050
Instituto Federal do Maranhão, Brasil
E-mail: carmen.rocha@ifma.edu.br
Gildênia Lima Monteiro
ORCID: https://orcid.org/0000-0003-4154-3901
Universidade Estadual do Maranhão, Brasil
E-mail: maryholanda@gmail.com

\section{Resumo}

A presente pesquisa teve como finalidade analisar como se dar a comercialização dos produtos agrícolas da microrregião urbana de São Luís, no estado do Maranhão. Para o estudo, foram escolhidos, como público-alvo, produtores familiares e consumidores de hortifrutigranjeiros e alimentos comercializados em polos de distribuição na região de São Luís, no estado do Maranhão. Para isso, realizou-se pesquisas bibliográficas e documental, além da pesquisa de campo, na qual se utilizou de pesquisas, entrevistas, bem como verificação direta na coleta dos dados utilizados nas análises realizadas. Com a conclusão da pesquisa, constatou-se que a partir das abordagens teóricas e empíricas desenvolvidas no estudo, o objetivo tenha sido alcançado dentro da proposta de estudo proposto e não probabilístico. Nesse enfoque, a pesquisa considerou, como elemento basilar, a importância do pequeno produtor e da agricultura familiar na produção de alimentos no centro comercial de São Luís, além do atendimento ao mercado consumidor na região de estudo, alinhando, assim, a análise e discussão dos resultados às dimensões do desenvolvimento propostas pela pesquisa. Vale destacar que, no processo de comercialização, por exemplo, verificou-se, dentre outras características, a utilização de transporte próprio para o translado das mercadorias até os centros de comercialização, em embalagens sem identificação do nome do produtor, fato que se presente poderia colaborar para a logística e divulgação dos produtos oferecidos. Todavia, vale mencionar que a não divulgação das marcas e embalagens não se configura como elemento relevante na comercialização 
dos produtos, pois se verificou que os consumidores locais, em geral, confiam na procedência e qualidade dos produtos oferecidos pelos centros de comercialização - como as CEASAs.

Palavras-chave: Agricultores familiares; Mercado; Canais de comercialização.

\begin{abstract}
This research aimed to analyze how to commercialize agricultural products in the urban micro-region of São Luís, in the state of Maranhão. For the study, family farmers and consumers of horticultural products and foods sold in distribution centers in the region of São Luís, in the state of Maranhão, were chosen as target audience. For this, bibliographic and documentary research was carried out, in addition to field research, in which research, interviews were used, as well as direct verification in the collection of data used in the analyzes carried out. With the conclusion of the research, it was found that from the theoretical and empirical approaches developed in the study, the objective has been achieved within the proposed and not probabilistic study proposal. In this approach, the research considered, as a basic element, the importance of small producers and family farming in food production in the São Luís shopping center, in addition to serving the consumer market in the study region, thus aligning the analysis and discussion results to the dimensions of development proposed by the research. It is worth noting that, in the commercialization process, for example, it was verified, among other characteristics, the use of proper transport for the transfer of the goods to the commercialization centers, in packages without identification of the name of the producer, a fact that could be present collaborate for the logistics and dissemination of the products offered. However, it is worth mentioning that the nondisclosure of brands and packaging is not a relevant element in the marketing of products, as it was found that local consumers, in general, trust in the origin and quality of products offered by marketing centers - such as CEASAs .
\end{abstract}

Keywords: Family farmers; Market; Marketing channels.

\title{
Resumen
}

Esta investigación tuvo como objetivo analizar cómo comercializar productos agrícolas en la microrregión urbana de São Luís, en el estado de Maranhão. Para el estudio, se eligió como público objetivo a agricultores familiares y consumidores de productos hortofrutícolas y alimentos vendidos en los centros de distribución de la región de São Luís, en el estado de Maranhão. Para ello, se realizó una investigación bibliográfica y documental, además de una investigación de campo, en la que se utilizó la investigación, entrevistas, así como la verificación directa en la recolección de datos utilizados en los análisis realizados. Con la conclusión de la investigación, se encontró que a partir de los enfoques teóricos y empíricos desarrollados en el estudio, se ha logrado el objetivo dentro de la propuesta de estudio propuesto y no probabilístico. En este enfoque, la investigación consideró, como elemento básico, la importancia de los pequeños productores y la agricultura familiar en la producción de alimentos en el centro comercial São Luís, además de atender al mercado consumidor en la región de estudio, alineando así los resultados del análisis y la discusión. a las dimensiones de desarrollo propuestas por la investigación. Cabe señalar que, en el proceso de comercialización, por ejemplo, se verificó, entre otras características, el uso de transporte adecuado para el traslado de la mercadería a los centros de comercialización, en bultos sin identificación del nombre del productor, hecho que podría colaborar para la logística y difusión de los productos ofertados. Sin embargo, cabe mencionar que la no divulgación de marcas y empaques no es un elemento relevante en la comercialización de productos, ya que se encontró que los consumidores locales, en general, confían en el origen y la calidad de los productos que ofrecen los centros de comercialización como CEASA.

Palabras clave: Agricultores familiares; Mercado; Canales de comercialización.

\section{Introdução}

As feiras não têm uma data especifica de seu início, porém acredita-se que em 500 a.C. já haviam eventos que se assemelhavam ao que hoje é determinado de feira. Os primeiros relatos datados são dos séculos XI e XIV, das feiras medievais, que começaram a ocorrer devido a insatisfação da população com o comercio local. $\mathrm{O}$ termo feira significa dia santo, feriado ou dia de descanso, que eram usados pelos comerciantes para vender seus produtos, já que as pessoas não estariam trabalhando.

Comercialização compreende "o conjunto de atividades realizadas por instituições que se acham empenhadas na transferência de bens e serviços desde o ponto de produção inicial até que eles atinjam o consumidor final” (Piza; Welsh, 1968).

Entende-se por comercialização o desempenho de todas as atividades necessárias ao atendimento das necessidades e desejos dos mercados, planejando a disponibilidade da produção, efetuando transferência de propriedade de produtos, provendo meios para a sua distribuição física e facilitando a operação de todo o processo de mercado. 
A comercialização nas feiras é algo que influencia bastante na negociação com fornecedores e com os consumidores finais, tanto em relação ao transporte da carga, quanto a maneira que ela vai ser armazenada e por quanto tempo vai ficar no armazenamento até ser vendida para o consumidor final.

Nesse processo, segundo Leuthold, Junkus; Cordier (1989), para o produtor ou comerciante, a operação a futuro é antes de tudo uma forma de reduzir os riscos de mercado, assegurando um certo preço pelo produto que vai comprar ou vender em algum momento no futuro.

Em São Luís existem diversas feiras, com vários produtos disponíveis, dentre carnes, hortaliças, roupas, eletrônicos, etc. Focando apenas na parte agronômica, vemos uma grande disponibilidade de produtos, como: cheiro verde, cebolinha, verduras, frutas e muitos outros produtos, porém grande parte desses produtos não são fornecidos por produtores da região de São Luís, esses produtos, em sua maioria, vêm do estado do Ceará, devido ao seu preço competitivo em relação ao praticado por outros produtores.

Na região periférica de São Luís está localizado o polo de produção de muitos produtos vendidos em feiras na região, porém muitos sofrem do mesmo problema, a falta de assistência técnica para aprimorar a qualidade e aumentar a produtividade de suas hortas, outro fator que influencia bastante é o alto preço dos insumos para a produção.

Visto que, em sua maioria, são produtores que dependem da venda e não tem capital extra para investimento, o foco sempre é o subsidio do governo, onde o primeiro passo é levar informação de como administrar o negócio, escalar sua produção e aumentar sua produtividade, ou seja, prestar assistência técnica de todo o processo, da administração até a venda o produto, após feito isso, o governo entraria com o capital de investimento, visto que, os produtores já estariam com as informações necessárias para tocar o negócio da forma correta.

Assim, nosso objetivo de trabalho foi avaliar o destino da comercialização dos produtos hortifrutícola dos agricultores familiares da Microrregião da Aglomeração Urbana de São Luís, procurando conhecer a forma e estratégias de comercialização dos produtores familiares e as dificuldades encontradas no processo de comercialização.

\section{Material e Métodos}

A pesquisa foi realizada nas feiras livre dos municípios da Microrregião Aglomeração Urbana de São Luís, durante o mês de fevereiro de 2021, onde pode-se encontrar produtores dos quatro municípios: São Luís, São José de Ribamar, Raposa e Paço do Lumiar. É importante estudar os quatro municípios por dois motivos: o primeiro é pelo fato de que com uma maior divisão municipal do Estado em 1994/95, alguns produtores que antes faziam parte do município de São Luís, hoje podem residir em comunidades que atualmente fazem parte dos municípios de Paço do Lumiar e São José de Ribamar. O segundo, seria a possibilidade de análise de municípios próximos e com características muito próximas.

Nosso trabalho iniciou com a elaboração e desenvolvimento do questionário para posterior aplicação destes nas feiras livres distribuídas pela cidade de São Luís (Figura 1). A aplicação dos questionários e seleção das feiras foi feita com os membros e locais mais acessíveis. Os dados coletados, através da aplicação dos questionários, foram reunidos e tabulados. 
Figura 1. Aplicação de questionário junto aos produtores na feira.

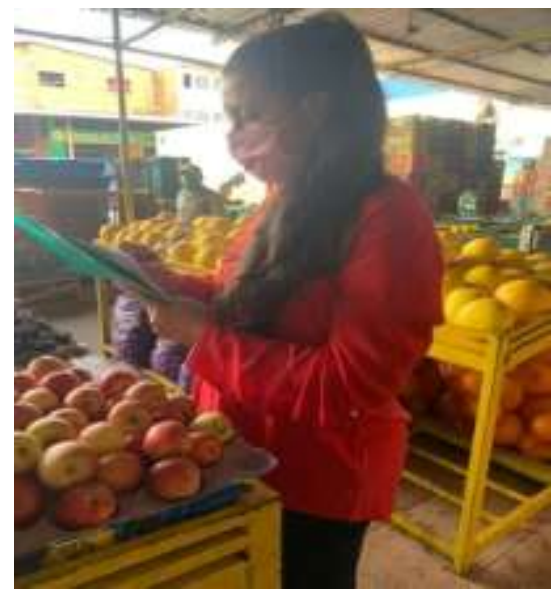

Fonte: Autores.

O público alvo da pesquisa foram os produtores da Microrregião Aglomeração Urbana de São Luís, que estão distribuídos nos quatro municípios, participantes das feiras livres dos bairros da região. É importante retratar e conhecer essa realidade, a fim de melhorar o modo como os produtos são ofertados nas feiras e a forma como eles chegam tanto para os feirantes quanto para os consumidores, assim a região sai ganhando de forma dupla, melhorando a qualidade de vida da população, com produtos processados de forma correta e com a melhoria de vida dos comerciantes.

A presente pesquisa utilizou os métodos quantitativos e qualitativos. Para Dalfovo et al. (2008), o método quantitativo caracteriza-se pelo emprego de quantificação, tanto nas modalidades de coleta de informações, quanto no tratamento desses por meio de técnicas estatísticas. O método qualitativo se caracteriza por um maior foco na compreensão dos fatos.

Após a coleta e tabulação dos dados, realizou-se a análise estatística. Todas as análises foram realizadas através dos Programas Excel (Microsoft Office Excel). A análise estatística será realizada através da análise descritiva com o uso da média. Os resultados estão apresentados em tabelas e gráficos com o objetivo de simplificar e tornar os dados mais facilmente perceptíveis, assim como, o uso de taxas percentuais.

\section{Resultados e Discussão}

O perfil dos entrevistados são de na maioria homens, sendo 55\% homens e $45 \%$ mulheres (Figura 2), com uma média de idade de 45 anos, na faixa de 21 a 69 anos.

Todos os produtores entrevistados são produtores de hortaliças, estando 50\% deles localizados em São Luís, 12,5\% em São José de Ribamar, 34,4\% em Paço do Lumiar e 3,1\% na Raposa (Figura 3). 
Figura 2. Percentual do gênero dos produtores Figura 3. Localização dos produtores entrevistados por município. entrevistados.

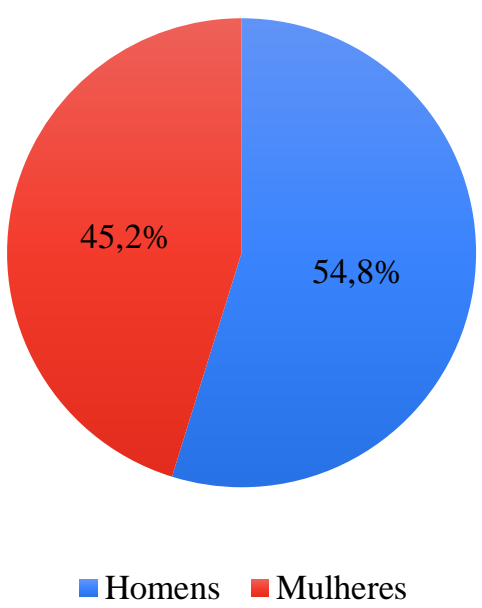

Fonte: Autores.

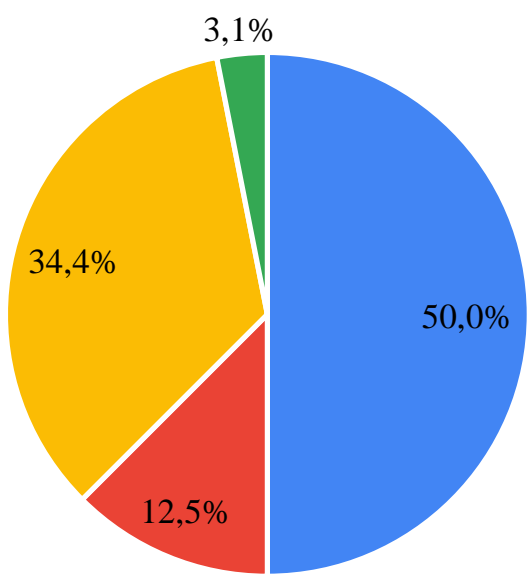

$$
\begin{array}{ll}
\text { - São Luis } & \text { - São Jose de Ribamar } \\
\text { - Paço do Lumiar } & \text { - Raposa }
\end{array}
$$

Fonte: Autores.

Ao serem questionados sobre as dificuldades encontradas na venda dos produtos agrícolas, os produtores apontaram a dificuldade em competir com os preços dos produtos que vem de fora do estado, produtos comprados por feirantes no CEASA e vendido nas feiras a preços mais baixos, outro ponto é a dificuldade do deslocamento de suas produções às feiras distribuídas pela cidade. As dificuldades encontradas no deslocamento citadas foram: as estradas e vias de acesso em estado de regular a péssimo, e a falta de transporte. Aquino et al. (2020), apontam o acesso precário às comunidades da microrregião aglomeração de São Luís como um fator que desfavorece a comercialização e escoamento da produção, podendo chegar a interromper essa comercialização em determinados períodos do ano.

Quanto aos meios de transporte utilizados para levar a produção agrícola das propriedades a forma mais utilizada é o fretamento de carros, que corresponde a 42,9\%, em seguida a utilização de carro próprio com 35,7\%, a coleta da produção nos pontos de coletas dos programas institucionais sendo 14,3\%, e carro emprestado, transporte público e bicicleta com 3,6\% (Figura 4). A forma de transporte e o acondicionamento dos produtos interfere diretamente sobre a sua qualidade, onde produtos hortícolas quando expostos a altas temperaturas e mal acondicionamento podem sofrer danos no qual diminuem a qualidade com a qual esses produtos chegam aos compradores e consumidores. Algumas soluções buscadas pelos produtores para contornarem dificuldades que atrapalham a comercialização dos produtos são: realizar o transporte dos produtos através de carros fretados, carros próprios e transporte público. 
Figura 4. Transporte utilizado para entrega dos produtos agrícolas dos produtores entrevistados.

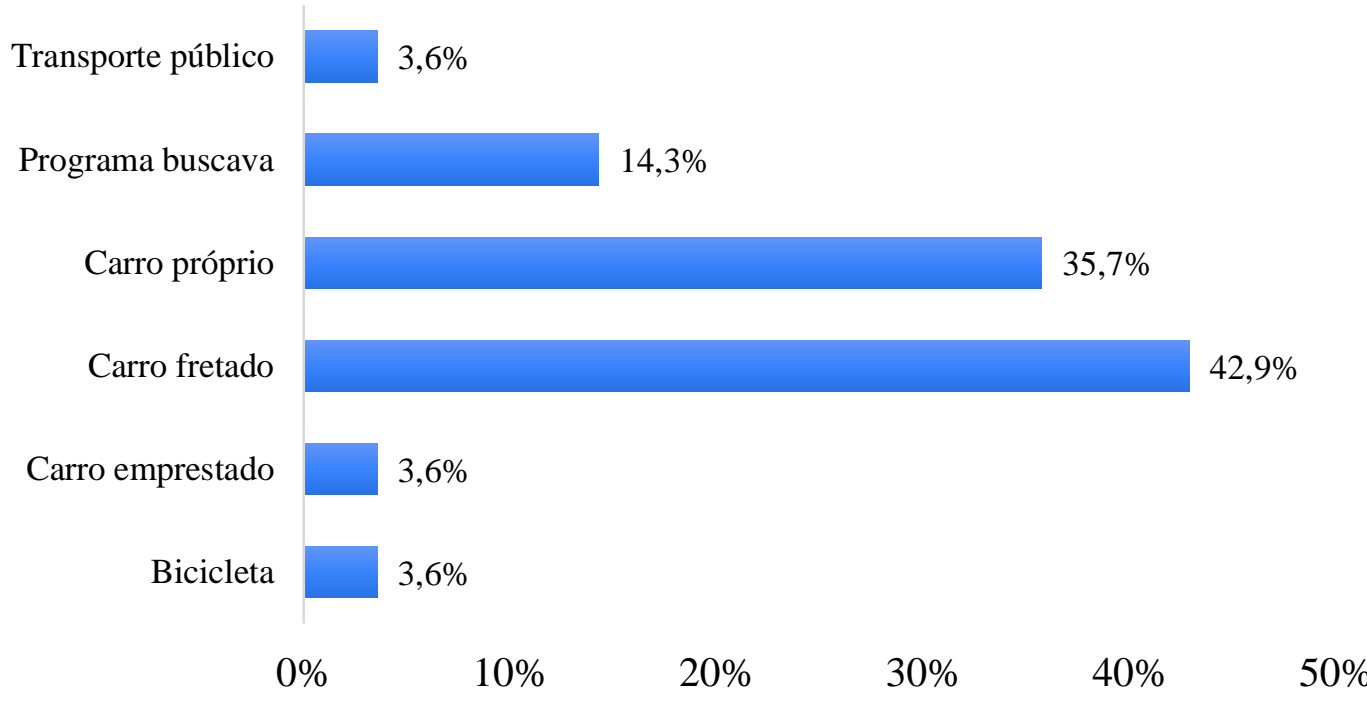

Fonte: Autores.

Os produtos agrícolas comercializados pelos produtores entrevistados são vendidos 93,5\% para programas institucionais como PAA e PNAE, 61,3\% para Feiras, 12,9\% para Consumidores de fora das comunidades e 51,6\% para Atravessadores (Figura 5).

Figura 5. Destino da comercialização dos produtos agrícolas dos produtores entrevistados.

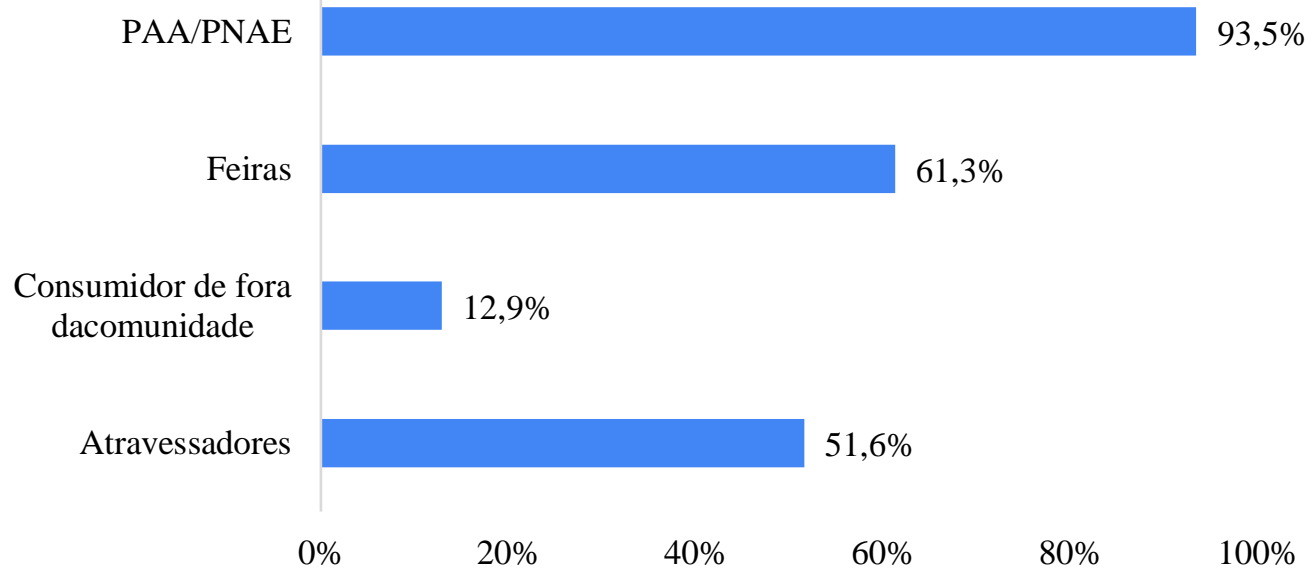

Fonte: Autores.

Percebe-se uma grande participação dos produtores entrevistados nos programas institucionais PAA e PNAE, no qual destinam parte de suas produções para entregas semanais, servindo estes como um bom canal de comercialização de parte da produção devido a sua periodicidade na compra e bons preços de compra comparados aos do mercado, que diariamente flutua com a oferta de produtos de fora do estado. Autores como Silva (2016) e Campos (2011), apontaram as vantagens de programas como estes para o desenvolvimento da produção familiar local, servindo de canal de comercialização seguro e vantajosos, 
diminuindo os riscos de perda ou diminuição das produções. As feiras também são um importante canal de comercialização para os produtores, visto que há um contato direto do produtor com o consumidor, sendo um circuito mais curto de comercialização, possibilitando um maior retorno financeiro, sem terceiro ou atravessadores. Da Silva et al. (2020) também trazem as feiras como importante canal de comercialização para a agricultura familiar e maior oportunidade de lucro, assim como potencializam uma conexão direta entre os agricultores e consumidores, possibilitando a formação da sua própria rede e construção de relações mútuas de confiança e reciprocidade entre os agentes envolvidos (Souza-Seidl; Billaud, 2015; Scarabelot; Schneider, 2012). Os atravessadores são uma forma de comercialização expressiva dos produtores entrevistados, no qual vendem parte de suas produções para eles dentro da propriedade a preços mais baixos ou mesmo dentro das feiras, repassando quantidades maiores a preços menores. A venda em circuitos mais longos diminui a rentabilidade do produtor e podem gerar uma dependência financeira em relação aos atravessadores (Dos Santos et al., 2018). Chuquillanque et al (2015) citam vantagens pela ausência de um atravessador no circuito como: clientes fixos, preço justo, pagamento à vista e possibilidade de interagir com os consumidores. Um outro modo de comercialização apontado foi a venda para consumidores de fora da comunidade que ficam próximos às propriedades e vão em busca de alimentos frescos e com qualidade.

\section{Conclusão}

Os resultados encontrados indicam que os programas institucionais PAA e PNAE, juntamente com as Feiras Livres, constituem os principais canais de comercialização dos produtos agrícolas dos produtores rurais da Microrregião Aglomeração Urbana de São Luís; os programas institucionais devido às vantagens em relação a segurança de venda e preço, e as feiras pelo encurtamento do circuito de comercialização trazendo maiores lucros e independência durante a comercialização.

A competitividade com os preços dos produtos vindo de fora do estado, juntamente com as péssimas condições de vias de acesso e com o meio de transporte, são os principais desafios encontrados para realizar a comercialização da produção. Estratégias que estejam ao alcance dos produtores podem estar sendo adotadas para contornarem essas situações, como: para competir com produtos mais baratos vindos de outros estados eles podem aumentar a quantidade de produtos vendidos para os outros canais de comercialização quando forem mais vantajosos do que competir com preços muito baixos nas feiras, fazendo o acompanhamento constante dos preços para uma melhor tomada de decisão da venda, podendo ate mesmo realizar contratos futuros com alguns compradores no atacado, logo, o acompanhamento e estudo dos canais de comercialização do mercado constituem uma importante estratégia para os produtores alcançarem maior lucratividade e correrem menos riscos na comercialização; a fretagem de veículos em conjunto pelos produtores é uma solução para o barateamento e garantia de transporte dos produtos dos produtores que não possuem veículos para isso, podendo ate mesmo ser adotado pelos que tem veículo próprio como forma mais barata de transporte; as vias de acesso por serem de competência das entidades públicas podem estar sendo acionada pelos sindicatos ou associações de produtores para que deem melhores condições de acesso a eles, já que esses locais são importantes polos produtivos e de geração de renda e trabalho.

\section{Referências}

Aquino, A. M et al. Análise da contribuição dos programas institucionais (paa, pnae e feira livre itinerante) na geração de renda e na qualidade de vida dos agricultores familiares da microrregião aglomeração urbana de são luís-ma. Extensão Rural em Foco: Apoio à Agricultura Familiar, Empreendedorismo e Inovação, 1, 173-182.

Brandt, S. A. Comercialização agrícola. Piracicaba: Livroceres, p. 195.

Campos, R. A. Agricultura familiar e políticas públicas: avaliação do Programa Nacional de Alimentação Escolar-PNAE no município de Campina da Lagoa/PR.

Chuquillanque, D. A. et al. (2015) Caracterização da produção agrícola e dos feirantes da agricultura familiar no Município de São Lourenço do Sul-RS. In: $V$ Congreso Latinoamericano de Agroecología-SOCLA. 
Research, Society and Development, v. 10, n. 5, e1310514632, 2021

(CC BY 4.0) | ISSN 2525-3409 | DOI: http://dx.doi.org/10.33448/rsd-v10i5.14632

Da Silva, D. V., \& Borges, J. J. R. P. (2020) As feiras-livres da agricultura familiar em Arapiraca, Alagoas, Brasil. Raízes: Revista de Ciências Sociais e Econômicas, 40(1), 84-101.

Dalfovo, M. S., Lana, R. A., \& Silveira, A. (2008) Métodos quantitativos e qualitativos: um resgate teórico. Revista interdisciplinar científica aplicada, 2(3), 113 .

Dos Santos, R. S. J. (2018) Percepção dos agricultores familiares que participam da feira de produtos orgânicos de Cruz das Almas.

Leuthold, R. M., Junku, J.C., \& Cordier, J. E. (1989). The Theory and Practice of Futures Markets.

Piza, C. T., \& Welsh, R.W., (1968). Introdução à Análise da Comercialização. Série Apostila n. ${ }^{\circ}$ 10. Departamento de Economia - ESALQ/USP, PiracicabaSP.

Scarabelot, M., \& Schneider, S. (2012) As cadeias agroalimentares curtas e desenvolvimento local-um estudo de caso no município de Nova Veneza/SC. Revista Faz Ciência, v. 14, n. 19, p. 101.

Silva, L. C. M. et al. Território rural de identidade Parque das Emas: fortalecimento das famílias assentadas em Jataí-GO. 2016.

Souza-Seidl, R., \& Billaud. J. P. (2005) O casamento entre os circuitos curtos e a agricultura de base. In. Brandenburg, A. Billaud. Jean-Paul, Lamine, C. Redes de Agroecologias: experiências no Brasil e na França Organizadores, Kariós Edições, 134-170. 